\title{
Thresholds of time dependent intergranular crack growth in a nickel disc alloy Alloy $720 \mathrm{Li}$
}

\author{
Hangyue $\mathrm{Li}^{1, \mathrm{a}}$, Joe Fisk ${ }^{1}$, Lik-Beng Lim ${ }^{2}$, Steve Williams $^{2}$, and Paul Bowen ${ }^{1}$ \\ ${ }^{1}$ School of Metallurgy and Materials, The University of Birmingham, Birmingham B15 2TT, UK \\ 2 Rolls-Royce plc., PO box 31, Derby DE24 8BJ, UK
}

\begin{abstract}
At high temperatures in air, introducing a dwell period at the peak stress of fatigue cycles promotes time dependent intergranular crack growth which can increase crack growth rates by upto a few orders of magnitude from the rates of transgranular fatigue crack growth in superalloys. It is expected that time dependent intergranular crack growth in nickel-based superalloys may not occur below a critical mechanical driving force, $\Delta K_{\mathrm{th}-\mathrm{IG}}$, analogous to a fatigue threshold $\left(\Delta K_{\mathrm{th}}\right)$ and a critical temperature, $T_{\mathrm{th}}$. In this study, dwell fatigue crack growth tests have been carefully designed and conducted on Alloy $720 \mathrm{Li}$ to examine such thresholds. Unlike a fatigue threshold, the threshold stress intensity factor range for intergranular crack growth is observed to be highly sensitive to microstructure, dwell time and test procedure. The near threshold crack growth behaviour is made complex by the interactions between grain boundary oxidation embrittlement and crack tip stress relaxation. In general, lower $\Delta K_{\text {th-IG }}$ values are associated with finer grain size and/or shorter dwell times. Often a load increasing procedure promotes stress relaxation and tends to lead to higher $\Delta K_{\text {th-IG. When there is limited }}$ stress relaxation at the crack tip, similar $\Delta K_{\text {th-IG }}$ values are measured with load increasing and load shedding procedures. They are generally higher than the fatigue threshold $\left(\Delta K_{\mathrm{th}}\right)$ despite faster crack growth rates $(\mathrm{d} a / \mathrm{d} N)$ in the stable crack growth regime. Time dependent intergranular crack growth cannot be activated below a temperature of $500^{\circ} \mathrm{C}$.
\end{abstract}

\section{Introduction}

At high temperature in air, introducing a dwell period into fatigue cycles can cause cyclic crack growth rates to increase in nickel based superalloys, associated with a change of crack morphology from transgranular to intergranular [1]. Compared to traditional disc alloys, modern nickel based superalloys have higher yield strength and creep resistance to meet the requirement of improved performance and fuel efficiency. However rapid crack growth may arise due to environmental attack at temperatures below those at which significant creep can occur. Hence understanding environmentally assisted intergranular crack growth is important to lifing of engine components. Most studies have concentrated on the stable crack growth regime, in which very rapid crack growth was often observed. Achieving adequate component life, therefore, relies on understanding thresholds and near threshold crack growth.

It has been confirmed that at high temperatures in air an oxide intrusion can form ahead of the crack tip [2,3] as a result of oxygen ingress along grain boundaries. The advance of the crack can therefore result from subsequent fracture of such oxide intrusions. Naturally, one would expect the threshold stress intensity factor, $K_{\text {th-IG }}$, to be related to the fracture toughness of oxide

\footnotetext{
${ }^{\text {a }}$ Corresponding author: h.y.li.1@bham.ac.uk
}

intrusions. Although the fracture toughness of all types of oxides are relatively small [4], the time dependent crack growth will occur if the applied stress intensity factor exceeds a threshold value which is determined by the compressive residual stress induced by volume expansion upon formation of oxide intrusion [5]. Indeed such a threshold has been explored by Chan et al. [6] through a numeric approach and variable threshold values were predicted corresponding to oxidation of different constituent phases. The formation of different constituents of oxides was confirmed and ultimately observed to dictate different crack growth behaviour in an advanced RR1000 nickel disc alloy [7]. However, it is suggested that it is the kinetics of crack tip stress relaxation that plays a significant role on the constituent and the rupture of oxide intrusions ahead of the crack tip [1,7]. It is also likely that crack growth behaviour is extremely sensitive to microstructure variations with a reduction of external stress intensity factor towards the time dependent threshold value [7].

Corresponding to the theoretic predictions, experimental data of $K_{\text {th-IG }} / \Delta K_{\text {th-IG }}$ in the open literature are scarce, largely due to lack of appropriate testing procedures. A stair-case load increasing method, which is commonly employed in the determination of the threshold of room temperature stress corrosion cracking, $\mathrm{K}_{I S C C}$, was advocated by Kim et al. to be used in other materialenvironmental systems where crack growth occurs at 
Table 1. Composition of Alloy 720Li (in wt \%).

\begin{tabular}{|l|l|l|l|l|l|l|l|l|l|}
\hline Cr & Co & Mo & W & Al & Ti & $\mathbf{Z r}$ & $\mathbf{B}$ & $\mathbf{C}$ & $\mathbf{N i}$ \\
\hline 16 & 15 & 3.0 & 1.25 & 2.5 & 5.0 & 0.035 & 0.015 & 0.015 & Bal \\
\hline
\end{tabular}

relatively low stress intensities and at high time-based rates [8]. A higher $K_{\text {th-IG }}$ was indicated under hold time cycling than baseline fast cycling for IN 718 at $649^{\circ} \mathrm{C}$ in air [8].

The current study focused on characterisation of the thresholds for environmentally assisted, time dependent, intergranular crack growth for a nickel disc alloy Alloy 720Li. An experimental method was developed, with which various factors and the varied nature of $\Delta K_{\text {th-IG }}$ were investigated in detail. In addition, the limit of temperature, $T_{\text {th }}$, below which environmentally assisted intergranular crack growth cannot happen, was measured.

\section{Experimental}

The material employed in this study was nickel based superalloy Alloy 720Li. The composition of the alloy is shown in Table 1 . The cast and wrought material was solution heat treated at $1105^{\circ} \mathrm{C}$ (below the $\gamma^{\prime}$ solvus) for $4 \mathrm{~h}$ and subsequently oil quenched. This was followed by a two-step ageing heat treatment consisting of $24 \mathrm{~h}$ at $650{ }^{\circ} \mathrm{C}$ and $16 \mathrm{~h}$ at $760{ }^{\circ} \mathrm{C}$. A tri-modal distribution of gamma prime resulted, denoted as primary, secondary and tertiary gamma prime $\left(\mathrm{p}-\gamma^{\prime}, \mathrm{s}-\gamma^{\prime}\right.$ and $\left.\mathrm{t}-\gamma^{\prime}\right)$ respectively. Due to the precipitation of large $\mathrm{p}-\gamma^{\prime}$ on the grain boundaries during solution heat treatment, a fine grained microstructure typically in the range of 4-13 $\mu \mathrm{m}$ was obtained. Variations in mean grain size and grain size distribution were confirmed between test pieces, despite the same processing and heat treating conditions being applied.

Test pieces with a $7 \times 7 \mathrm{~mm}^{2}$ square cross-section in the gauge length were machined from different disc forgings. A sharp notch was cut on to one corner edge to enable initiation of a quarter-circular crack under axial tensile fatigue loading. All tests were carried out under load control using an Instron 8862 electrical screw driven test machine and a direct current potential drop (d.c.p.d.) technique was employed to automatically monitor the growth of cracks.

The determination of thresholds of stress intensity factor range for intergranular and transgranular crack growth concentrated on a temperature of $650{ }^{\circ} \mathrm{C}$ and a stress ratio of 0.1 . In addition to a standard load shedding procedure as used for the determination of fatigue threshold, an alternative load increasing approach was also applied. In this approach, a sharp crack was produced by fatigue loading $(\sim 1 \mathrm{~Hz})$ which had a small associated plastic zone size. This was achieved by gradually reducing the external mechanical driving force, $\Delta \mathrm{K}$, to close to the fatigue threshold. Then dwell fatigue cycling was applied either at the same peak load or about $10 \%$ below. Once no crack extension was confirmed after two days, a small increase $(<10 \%)$ in peak and load range was applied and the test was allowed to run for another two days. This sequence was repeated until continuous crack advance was detected and the load range at this point was used to calculate the associated $\Delta K$ value, which was then claimed to be a valid $\Delta K_{\text {th-IG }}$ if an intergranular morphology was confirmed from the fracture surface. Note the dwell loading waveforms used in this study comprised a trapezoidal waveform of $1-X-1-1$. The dwell time of " $X$ " seconds was introduced at the peak load, and the ramp times and hold period at minimum load were all set to 1 second. By using different dwell times of $120 \mathrm{~s}$, $1200 \mathrm{~s}$ and $3600 \mathrm{~s}$, the influence of crack tip creep strain accumulation could be examined. The minimum dwell time of 120 seconds was selected as being just enough to produce a full intergranular fracture surface morphology whilst minimising the amount of stress relaxation at the crack tip. The resultant $\Delta K_{\text {th-IG }}$ provides a lower limit for intergranular crack growth.

It is understood that intergranular crack growth in nickel based superalloys is thermally activated. In order to measure such a temperature limit, below which intergranular crack growth becomes undetectable, a $3600 \mathrm{~s}$ dwell loading waveform (1-3600-1-1, $R=0.1$ was utilised to eliminate the contribution of fatigue. The test was started with a low temperature of $440^{\circ} \mathrm{C}$ while applying a high mechanical driving force $\Delta K$ of $\sim 30 \mathrm{MPa} \sqrt{\mathrm{m}}$ on a sharp fatigue precrack to ensure that $\Delta K_{\text {th-IG }}$ will be well exceeded once the temperature threshold $T_{\text {th }}$ is met. The test temperature was increased by $10^{\circ} \mathrm{C}$ after 48 hours if continuous crack growth was not observed. When crack advance was recorded, the temperature was kept constant and the crack was allowed to grow through a certain distance. In such a manner the temperature that can produce sustainable crack advance can be measured and was considered to be the temperature threshold if fully intergranular morphology was confirmed.

For one particular test, multiple loading waveforms were adopted. However they were arranged such that no influence of prior thermal and loading history would be induced. The sequence of this test was: (1) Fatigue $(1 \mathrm{~Hz})$ with load shedding to grow a crack down to $\Delta K_{\text {th }}$ at $650{ }^{\circ} \mathrm{C}$; (2) 1-3600-1-1 cycling, while the temperature was increased by steps from 440 to $510^{\circ} \mathrm{C}$ to determine $T_{\text {th }}$, (3) raising temperature back to $650^{\circ} \mathrm{C}$ and re-sharpening the crack by fatigue at $1 \mathrm{~Hz}$; (4) 1-120-1-1 cycling with load shedding to determine $\Delta K_{\text {th-IG }}$; (5) fatigue $(1 \mathrm{~Hz})$ at $650{ }^{\circ} \mathrm{C}$ to mark the crack front; and (6) fatigue to failure at room temperature. The test sequence is clearly marked on the fracture surface, as shown in Fig. 1.

After testing, all the fracture surfaces were examined in SEM to verify the failure mechanism. Metallographic samples were also made to characterise grain size and crack growth path.

\section{Results and discussion}

\section{1. $\Delta K_{\text {th-IG }}$ and $T_{\text {th }}$}

The results obtained from the above mentioned test (Fig. 1) are shown in Fig. 2. In this particular test, $\Delta K_{\text {th-IG }} 120 \mathrm{~s}$ dwell) and $\Delta K_{\text {th }} 1 \mathrm{~Hz}$ ) were both measured with a load shedding test procedure, and $T_{\text {th }}$ was measured with a temperature increasing procedure $(3600 \mathrm{~s}$ dwell). The shape of the crack growth curve for $120 \mathrm{~s}$ dwell 


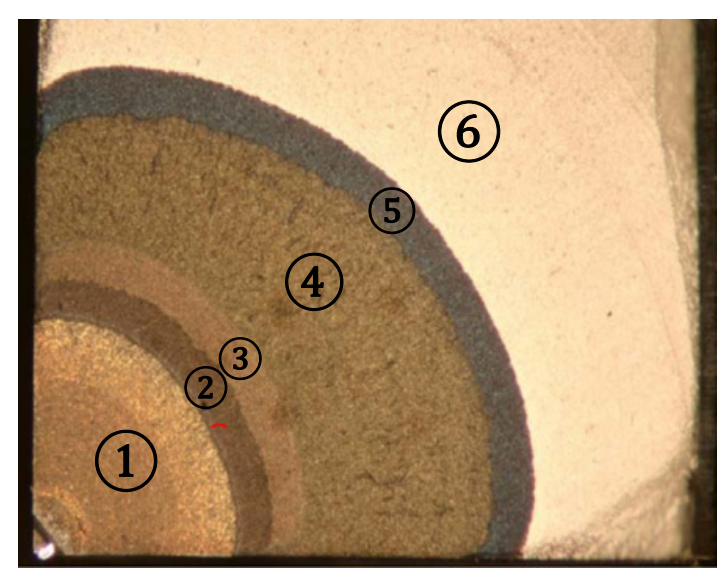

Figure 1. Optical macrograph of a tested sample showing different regions resulting from various loading waveforms employed.

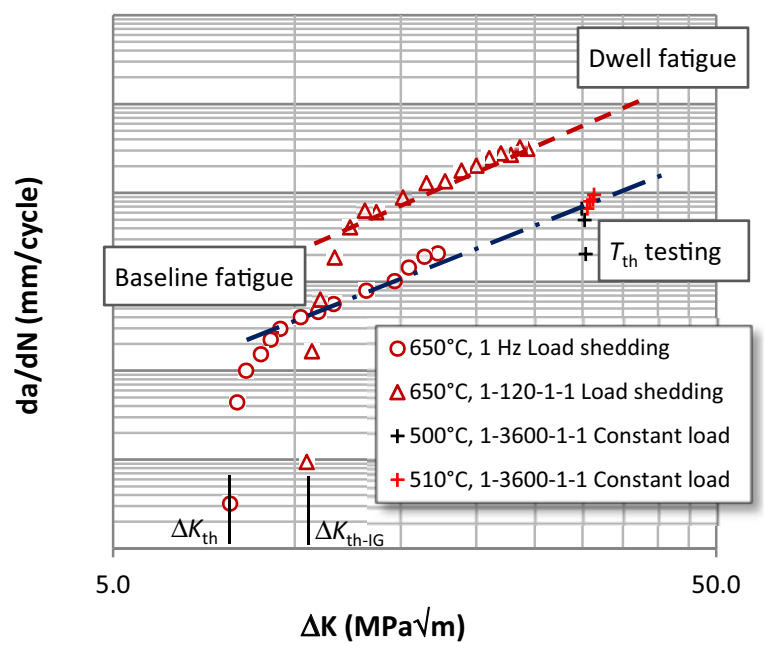

Figure 2. $\mathrm{da} / \mathrm{dN} \sim \Delta K$ curves for a single test experiencing a sequence of fatigue and dwell loading at $650{ }^{\circ} \mathrm{C}$ in air.

fatigue is very similar to that of baseline fatigue; both feature a near threshold regime and a stable crack growth regime. However the crack growth rates for $120 \mathrm{~s}$ dwell fatigue in the stable crack growth regime are $\sim 10$ times faster than those of baseline fatigue at the comparable $\Delta \mathrm{K}$ values. This is attributed to a complete transition from transgranluar crack growth to intergranular with the introduction of $120 \mathrm{~s}$ dwell at the peak load. Figure 3 demonstrates such a transition corresponding to a change in loading waveform. The mechanism that accounts for the intergranular crack growth at $650{ }^{\circ} \mathrm{C}$ is likely to be purely environmentally related, as the crack growth acceleration disappears in vacuum (the results will be reported elsewhere). Below a temperature at which the creep is not significant, the intergranular crack growth mechanism has been determined to be stress assisted grain boundary oxidation (SAGBO) $[9,10]$ which involves forming oxide intrusions ahead of the crack tip and their rupture under the influence of the crack tip stress field $[5,7]$.

It is interesting to observe in Fig. 2 that $\Delta K_{\text {th-IG }}$ is noticeable higher than $\Delta K_{\text {th }}$ when both are obtained

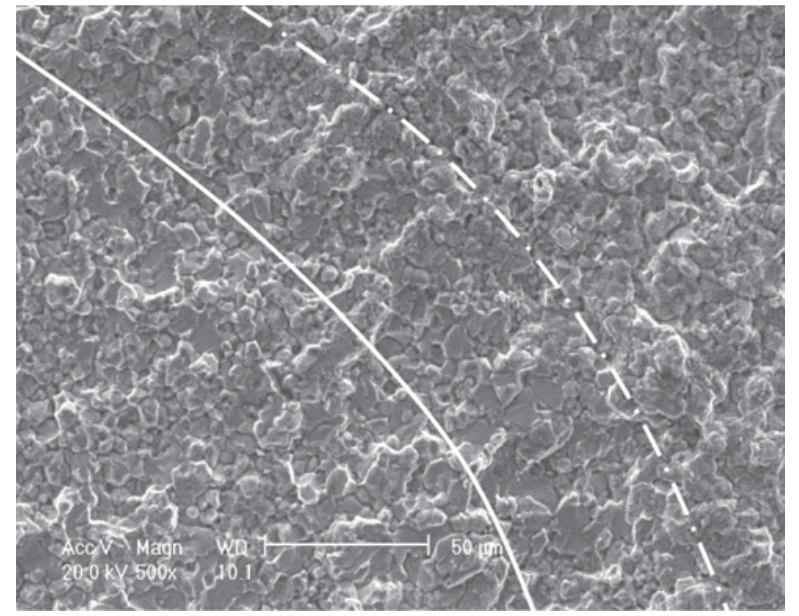

Figure 3. SEM fractograph showing the transition of fracture surface morphology corresponding to switching from fatigue loading to $120 \mathrm{~s}$ dwell cycling. The end of fatigue precracking $(1 \mathrm{~Hz})$ is marked by solid line. Transition to fully intergranular morphology under $120 \mathrm{~s}$ dwell, after a small amount of initial growth in a transgranular manner below $\Delta K_{\text {th-IG }}$ is marked by the dashed line.

by a load shedding method. The corresponding values are $10.5 \mathrm{MPa} \sqrt{\mathrm{m}}$ and $7.8 \mathrm{MPa} \sqrt{\mathrm{m}}$ respectively. It is understood that the mechanism for crack growth in both cases is different. The $\Delta \mathrm{K}_{\mathrm{th}}$, results from cyclic crack tip plasticity, whereas $\Delta K_{\text {th-IG }}$ represents a critical external mechanical driving force for environmental embrittlement to take effect, the physical meaning of which is not yet fully understood in the literature. Based on an earlier work [5] it is suggested that $\Delta K_{\text {th-IG }}$ may be related to a critical external mechanical driving force at which oxide intrusions ahead of the crack tip can no longer remain intact and start to crack. Although the fracture toughness of oxides are usually very small, $<2 \mathrm{MPa} \sqrt{\mathrm{m}}[4]$, they can be protected by compressive stresses resulting from volume expansion upon formation, constraint from the matrix, and crack tip blunting due to localised creep deformation [7]. Hence more external mechanical driving force is needed for crack growth to occur.

The $T_{\text {th }}$ was found to be $510^{\circ} \mathrm{C}$ although limited crack advance $(0.1 \mathrm{~mm})$ was observed at $500^{\circ} \mathrm{C}$. However it was not enough to stimulate continuous crack growth and the crack stopped growing after 203 cycles $(3600 \mathrm{~s}$ dwell). When the temperature was increased to $510^{\circ} \mathrm{C}$, the crack growth rate resumed and continued. Intergranular morphology was confirmed on the fracture surface. Therefore, $510^{\circ} \mathrm{C}$ was determined to be the threshold, $T_{\text {th. }}$.

Note that although intergranular crack growth can be actuated at $T_{\text {th }}$, the crack growth rate is very slow under $3600 \mathrm{~s}$ dwell fatigue loading and is similar to that of transgranular fatigue crack growth. Due to the competition between the two failure mechanisms, intergranular crack growth may not be observed with a shorter dwell time, which has more cycles in a given time period and hence biases the crack growth mechanism towards fatigue. Although the temperature may be low around $T_{\text {th }}$ or any creep accumulation to occur, potential crack blunting may 


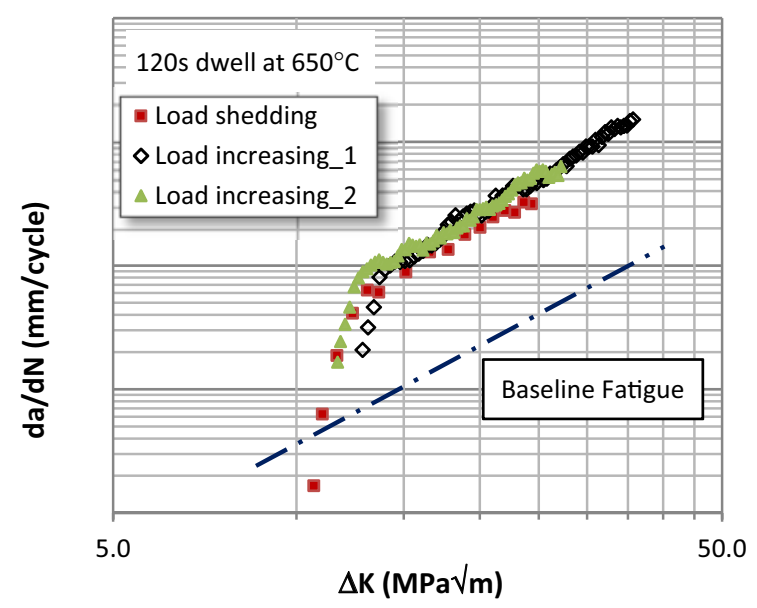

Figure 4. Comparison of da/dN $\sim \Delta K$ curves between different threshold testing procedures.

still take place during dwell cycling below $T_{\text {th }}$, which could lead to an increase in $T_{\text {th }}$. It is expected that $T_{\text {th }}$ value is microstructure dependent.

\subsection{Effect of testing procedure}

As mentioned before, selection of dwell time may affect the dominant failure mechanism around $T_{\mathrm{th}}$. It is postulated that a minimum dwell time is required to transfer transgranular crack growth to fully intergranular crack growth. At high temperatures this minimum time can be shorter as the rates of oxidation reactions are significantly dependent on temperature. $120 \mathrm{~s}$ dwell was found to result in completely intergranular crack growth morphology at $650^{\circ} \mathrm{C}$. Two tests were performed with an alternative load increasing procedure. The results from both testing procedures are compared in Fig. 4.

In Fig. 4, the crack growth curves from all three tests in the stable crack growth region overlap. In the near threshold region, in addition to a small difference in $\Delta K_{\text {th-IG }}$ observed between the two tests that used the load increasing procedure, which will be discussed in the following sections, there seems to be a subtle difference between the crack growth curves obtained by load shedding and load increasing procedures. Under the load shedding procedure, crack growth slowed with extension of the crack and can carry on growing at very low rates. In contrast, crack growth accelerated sharply upon reaching a critical value after long incubation under lower $\Delta K$ values with a load increasing procedure. A lower threshold of $10.5 \mathrm{MPa} \sqrt{\mathrm{m}}$ resulted from the loading shedding method, compared to 11.3 and $12.8 \mathrm{MPa} \sqrt{\mathrm{m}}$ obtained with the load increasing method. Such difference is likely to be attributed to a potential effect of oxide wedging with the load shedding procedure. It was decided that the load increasing approach is to be used to determine $\Delta K_{\text {th-IG }}$ for the majority of tests as crack growth in real components should be in a manner of increase stress intensity associated with the extension of the crack.

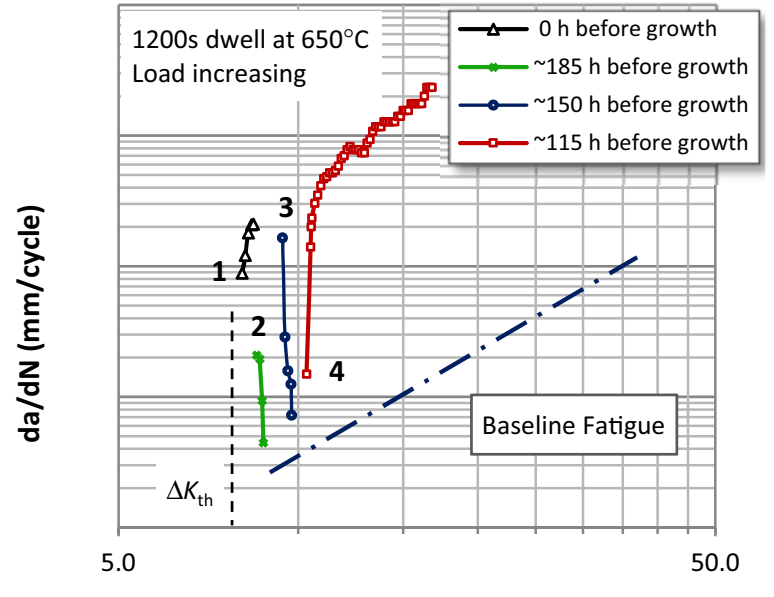

$\Delta \mathrm{K}(\mathrm{MPa} \sqrt{\mathrm{m}})$

Figure 5. da/dN $\sim \Delta K$ curves obtained from $1200 \mathrm{~s}$ dwell testing at $650^{\circ} \mathrm{C}$ in air.

\subsection{Effect of thermal exposure under stress}

An interesting phenomenon was observed when employing a load increasing test procedure as demonstrated in Fig. 5. After fatigue precracking, a sharp crack was prepared with a final $\Delta K$ of around $8 \mathrm{MPa} \sqrt{m}$ The crack was immediately transferred to a $1200 \mathrm{~s}$ dwell waveform with the same $\Delta K$ ith the expectation that $\Delta K_{\text {th-IG }}$ would be higher based on the previous observations from the $120 \mathrm{~s}$ dwell tests. Surprisingly the crack grew immediately, hence it took no time at all to initiate crack growth and the crack accelerated (marked as " 1 " in Fig. 5). It seemed that the $\Delta K_{\text {th-IG }}$ of this particular testpiece is below $8 \mathrm{MPa} \sqrt{m}$. The dwell loading was therefore interrupted and the $1 \mathrm{~Hz}$ load shedding was put back again to re-prepare the crack for threshold testing. For the second attempt, the $1200 \mathrm{~s}$ dwell waveform was begun with a $\Delta K$ of $5 \mathrm{MPa} \sqrt{\mathrm{m}}$. The crack had not grown in $\sim 185 \mathrm{~h}$ until the $\Delta K$ was increased step by step to around $8.5 \mathrm{MPa} \sqrt{\mathrm{m}}$ when the crack grew. It started with a relatively high rate initially but gradually slowed until it finally stopped (marked as " 2 " in Fig. 5). A load increase was needed again to resume crack growth at $9.4 \mathrm{MPa} \sqrt{\mathrm{m}}$. This time the crack stayed idle for $\sim 150 \mathrm{~h}$ before growth. But again it was not sustainable ("3" in Fig. 5). Continuous crack growth was not observed until another increase of $\Delta K$ to $10.4 \mathrm{MPa} \sqrt{\mathrm{m}}$ was applied.

Apparently the hold time prior to crack growth has a significant impact on $\Delta K_{\text {th-IG }}$ and near threshold crack growth. It is likely that with some exposure at high temperatures, $650{ }^{\circ} \mathrm{C}$ in the current study, and when kept below $\Delta K_{\text {th-IG }}$, a sharp crack would become blunt with the aid of local creep accumulation. Consequently crack growth would become harder as the stresses relaxed and redistributed ahead of the crack tip. Another possibility is that the material may overage, which could enable even faster stress relaxation. Clearly this test proves that an increase of $\Delta K_{\text {th-IG }}$, from $<8 \mathrm{MPa} \sqrt{\mathrm{m}}<10.4 \mathrm{MPa} \sqrt{\mathrm{m}}$ can be achieved by stressed thermal exposure prior to crack growth. Note that such an effect is analogous to the role plastic strain plays on fatigue crack growth at lower temperatures. 


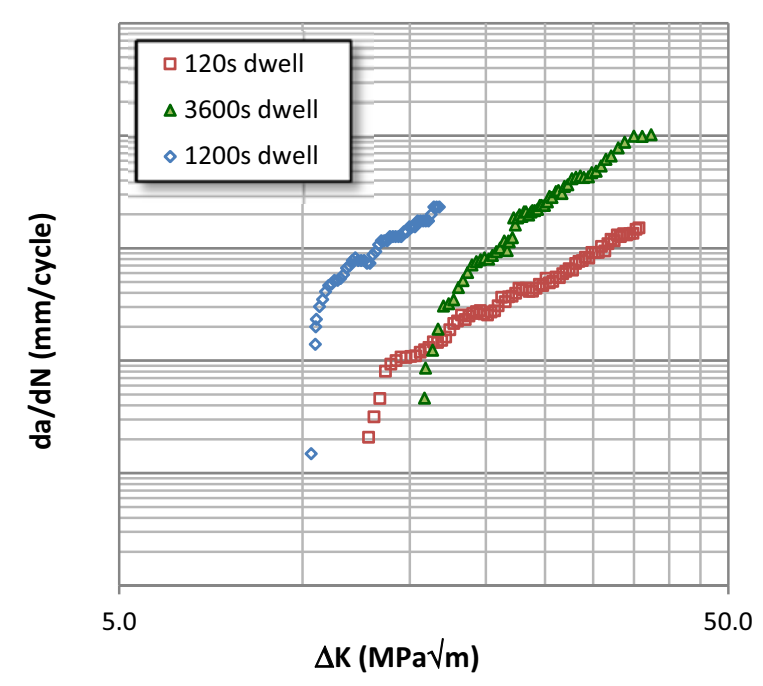

Figure 6. Comparison of $\mathrm{da} / \mathrm{dN} \sim \Delta K$ curves obtained from different dwell times at $650{ }^{\circ} \mathrm{C}$ in air.

\subsection{Effects of dwell time}

Again using a load increasing procedure, threshold tests were also performed using other dwell times such as $1200 \mathrm{~s}$ and $3600 \mathrm{~s}$. A comparison of crack growth curves between different dwell times is shown in Fig. 6. Note that all tests had been exposed for some time before reaching continuous crack growth. Although intergranular crack growth morphology was confirmed for all three dwell times, it is anticipated that the stress state can be influenced by the loading frequency. Similar to the effect of stressed thermal exposure below threshold, fewer numbers of unloading and loading cycles in a fixed time period promotes stress relaxation (crack blunting), and hence a higher $\Delta K_{\text {th-IG }}$ may incur. This is exactly what has been observed for the test with $3600 \mathrm{~s}$ dwell. $15.9 \mathrm{MPa} \sqrt{\mathrm{m}}$ was measured, compared to $12.8 \mathrm{MPa} \sqrt{\mathrm{m}}$ measured for $120 \mathrm{~s}$ dwell. But there was an exception, the $\Delta K_{\text {th-IG }}$ measured using $1200 \mathrm{~s}$ dwell time yield a $\Delta K_{\text {th-IG }}$ value of 10.4 $\mathrm{MPa} \sqrt{\mathrm{m}}$ which is lower than that for $120 \mathrm{~s}$ dwell. It was later confirmed that another factor could also affect threshold value and dwell fatigue crack growth, and this factor is microstructure.

\subsection{Effect of microstructure}

Although microstructure has been reported in literature to affect environmentally assisted intergranular crack growth, severe sensitivity to microstructure was only likely to be discovered with the employment of long dwell time and under lower values of external mechanical driving force, e.g. near threshold regime [7]. For the investigated alloy, uneven grain size is common due to the cast and forged processing route undertaken. The reason for such unevenness is due to the inhomogeneous distribution of $\mathrm{p}-\gamma^{\prime}$ which could originate from ingot and be aligned into bands during subsequent forging processes to produce billet. Figure 7 compares the microstructure between two test pieces that had been tested under $1200 \mathrm{~s}$ and $120 \mathrm{~s}$ dwell load waveforms.

The unusual low threshold value and fast crack growth rates observed in the $1200 \mathrm{~s}$ dwell test is likely to be

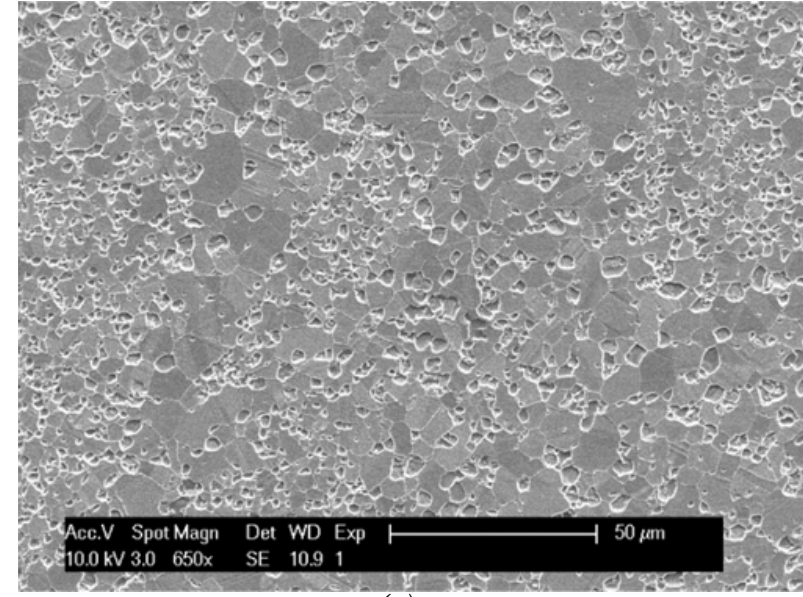

(a)

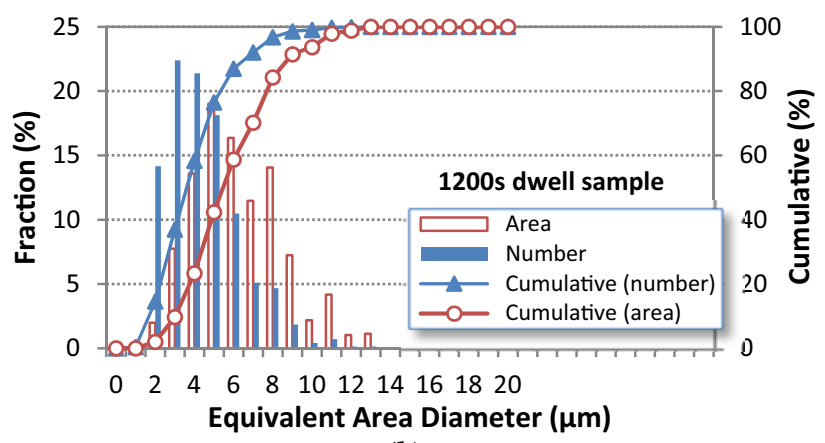

(b)

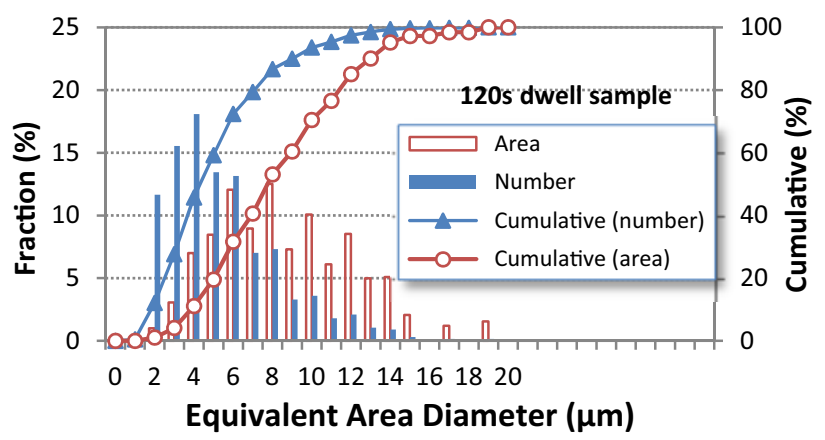

(c)

Figure 7. (a) Typical microstructure of Alloy 720Li after cast and wrought processing and heat treatment, (b) and (c) histograms showing grain size distributions in two samples (120 s and $1200 \mathrm{~s}$ dwell).

caused by a finer grain microstructure as confirmed by the histograms in Figs. $7 \mathrm{~b}$ and $7 \mathrm{c}$. The average grain size of the $1200 \mathrm{~s}$ dwell test piece is $3.9 \mu \mathrm{m}$, whereas it is $5.0 \mu \mathrm{m}$ for the $120 \mathrm{~s}$ dwell test piece. The difference in average grain size does not seem large. However the cumulative area fraction of small grains $(<5 \mu \mathrm{m})$ is significantly lager in the $1200 \mathrm{~s}$ dwell sample, $42 \%$, than that of $120 \mathrm{~s}$ dwell sample, $20 \%$ (compare Fig. $7 \mathrm{~b}$ to Fig. 7c). It is evident that having significant proportion of ultra fine grains increases the susceptibility of the alloy to environmental embrittlement.

Further evidence can also be collected on the fracture surface in the $1 \mathrm{~Hz}$ fatigue region. As compared in Fig. 8, the crack growth even turned intergranular around regions 


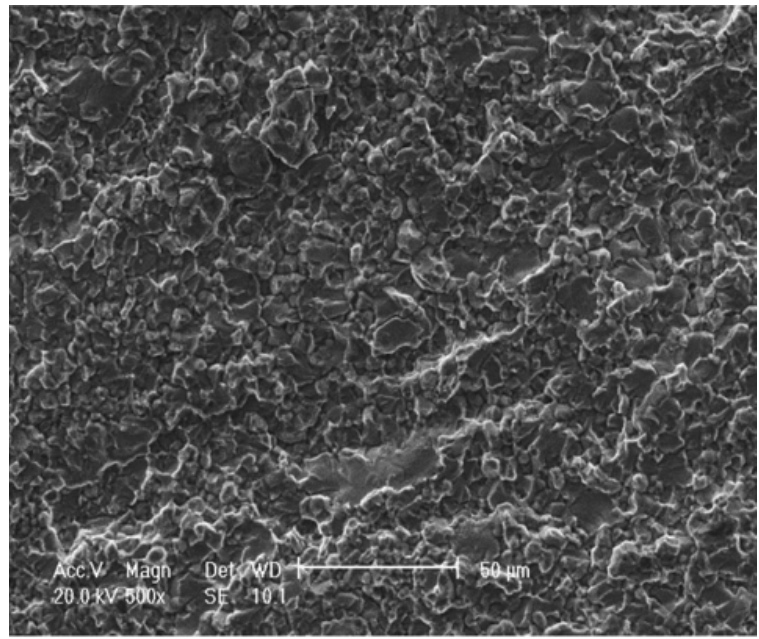

(a)

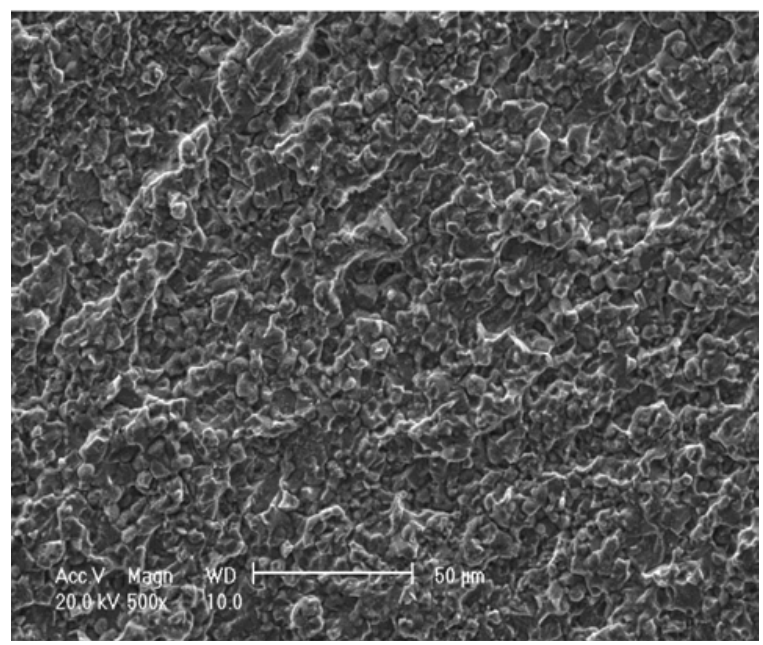

(b)

Figure 8. Comparison of fractographs between the two samples: (a) $120 \mathrm{~s}$ dwell sample, and (b) $1200 \mathrm{~s}$ dwell sample.

of finer grains and stayed transgranular in the areas of coarser grains. The proportion of intergranular areas is significant larger in $1200 \mathrm{~s}$ dwell test than that in the $120 \mathrm{~s}$ dwell test. It is evident that the microstructure could be sensitised to environmental attack by having a significant proportion of very fine grains in Alloy $720 \mathrm{Li}$. Both reduction in $\Delta K_{\text {th-IG }}$ and increase in crack growth rate can result. Such microstructure should be avoided through processing control. A thorough understanding of the relationship between processing and microstructure is needed.

\section{Conclusions}

Environment assisted near threshold intergranular crack growth is complex and sensitive to various factors.
The test procedures adopted helped to clarify the influences of individual factors. The following conclusions can be drawn:

- The $\Delta K_{\text {th-IG }}$ as generally observed to be higher than the $\Delta K_{\text {th }}$ at a temperature of $650^{\circ} \mathrm{C}$ in air. Unlike $\Delta K_{\text {th }} \Delta K_{\text {th-IG }}$ can vary significantly according to microstructure, dwell time and prior stressed thermal exposure.

- Environmentally assisted intergranular crack growth cannot be activated below $510^{\circ} \mathrm{C}$ in Alloy $720 \mathrm{Li}$.

- For the investigated alloy and microstructure form, very fine grains that the microstructure contained have a significant impact on $\Delta K_{\text {th-IG }}$ and near threshold intergranular crack growth. The larger the area fraction of very fine grains and the smaller the average grain size, the more susceptible the microstructure is to environmental attack.

- Increased $\Delta K_{\text {th-IG }}$ can result from longer dwell times and stressed thermal exposure prior to its measurement due to crack tip stress relaxation induced by local creep deformation.

- Under the combination of having susceptible microstructure and limited thermal exposure, a $\Delta K_{\text {th-IG }}$ value equal to or below $\Delta K_{\text {th }}$ is possible.

The joint support of the UK Engineering and Physical Sciences Research Council (EPSRC) and Rolls-Royce plc under the Strategic Partnership is gratefully acknowledged.

\section{References}

[1] J. Telesman, T.P. Gabb, A. Garg, P. Bonacuse and J. Gayda, Superalloys 2008, ed. R.C. Reed et al., 807816 (2008)

[2] H.S. Kitaguchi, H.Y. Li, H.E. Evans, R.G. Ding, I.P. Jones, G. Baxter and P. Bowen, Acta Mater. 61, 1968-1981 (2013)

[3] L. Viskari, M. Hörnqvist, K.L. Moore, Y. Cao and K. Stiller, Acta Mater. 61 3630-3639 (2013)

[4] H.E. Evans, A.T. Donaldson, T.C. Gilmour, Oxid. Met. 52, 380 (1999)

[5] H.E. Evans, H.Y. Li and P. Bowen, Scripta Mater. 69, 179-182 (2013)

[6] K.S. Chan, M.P. Enright, J. Moody and S.H.K. Fitch, Metall. Mater. Trans. 45A, 287 (2014)

[7] H.Y. Li, J.F. Sun, M.C. Hardy, S.J. Williams, and P. Bowen, Acta Mat (to be published)

[8] S.S. Kim, S.J. Choe and K.S Shin, Met. Mater. 4, 15 (1998)

[9] Andrieu E, Molins R, Ghonem H, Pineau A. Mater Sci Eng A154, 21 (1992)

[10] R. Molins, G. Hochstetter, J.C. Chassaigne, E. Andrieu, Acta Mater. 45, 663 (1997) 